\title{
Jones matrix polarization-correlation mapping of biological crystals networks
}

O. G. Ushenko

Yu. O. Ushenko

L. Y. Pidkamin

M. I. Sidor

O. Vanchuliak

A. V. Motrich

M. P. Gorsky

I. Meglinskiy

Yu. F. Marchuk 


\title{
Jones matrix polarization-correlation mapping of biological crystals networks
}

\author{
O.G. Ushenko ${ }^{a}$, Yu. O. Ushenko ${ }^{a}$, L.Y. Pidkamin ${ }^{a}$, M.I. Sidor ${ }^{a}$, O. Vanchuliak ${ }^{b}$, A.V. \\ Motrich $^{\mathrm{a}}$, M.P. Gorsky ${ }^{\mathrm{a}}$, I.Meglinskiy ${ }^{\mathrm{c}}$, Yu. F. Marchuk \\ ${ }^{a}$ Chernivtsi National University, 2 Kotsyubinsky Str., Chernivtsi, 58012, Ukraine \\ ${ }^{\mathrm{b}}$ Bukovinian State Medical University, Chernivtsi, 58000, Ukraine \\ ${ }^{c}$ University of Oulu, P.O. Box 4500, Oulu, Finland
}

\begin{abstract}
It has been proposed the optical model of Jones-matrix description of mechanisms of optical anisotropy of polycrystalline films of human bile, namely optical activity and birefringence. The algorithm of reconstruction of distributions of parameters - optical rotation angles and phase shifts of the indicated anisotropy types has been elaborated. The objective criteria of differentiation of bile films taken from healthy donors and patients with cholelithiasis by means of statistic analysis of such distributions have been determined. The operational characteristics (sensitivity, specificity and accuracy) of Jones-matrix reconstruction method of optical anisotropy parameters were defined.
\end{abstract}

Keywords: polarization; Fourier optics and signal processing; imaging systems; medical and biological imaging

\section{INTRODUCTION}

The structure of biological layers can be considered as structurally inhomogeneous one $e^{1-3}$. Laser polarimetry was formed recently as a new separate approach within matrix optics ${ }^{4-27}$.

This research is aimed on generalization of optical anisotropy of optically thin layers of bile films and the development of the method of Jones-matrix reconstruction of anisotropy parameters of polycrystalline networks in the task of cholelithiasis early diagnostics.

\section{BRIEF THEORETICAL BACKGROUND}

In this research we have utilized the model description of phase anisotropy, $7,8,18-21$ (optical activity and linear birefringence) of polycrystalline structure of films of biological fluids developed in ${ }^{22-27}$.

We determined the following analytical algorithms for reconstructing the phase anisotropy parameters of such polycrystalline films.

$$
\begin{gathered}
\delta=\frac{2 \arccos \left(R_{11} \cos \Theta_{11}+R_{22} \cos \Theta_{22}\right)}{1+\frac{R_{12} \cos \Theta_{12}-R_{21} \cos \Theta_{21}}{R_{22} \cos \Theta_{22}-R_{11} \cos \Theta_{11}}} \\
\theta=\frac{2 \arccos \left(R_{11} \cos \Theta_{11}+R_{22} \cos \Theta_{22}\right)}{1+\frac{R_{22} \cos \Theta_{22}-R_{11} \cos \Theta_{11}}{R_{12} \cos \Theta_{22}-R_{21} \cos \Theta_{11}}}
\end{gathered}
$$

Biosensing and Nanomedicine X, edited by Hooman Mohseni, Massoud H. Agahi, Manijeh Razeghi, Proc. of SPIE Vol. 10352, 103520X · @ 2017 SPIE · CCC code: 0277-786X/17/\$18 · doi: 10.1117/12.2274262 


\section{ANALYSIS AND DISCUSSION OF EXPERIMENTAL DATA}

Two groups of polycrystalline bile films were investigated:

- Healthy donors (group 1) - 41 patients;

- Patients with cholecystitis (group 2) - 41 patients.

The measurements of coordinate distributions of Jones-matrix elements were performed in the polarymeter setup ${ }^{21}$.

On the basis of (1)-(2) for each pixel of CCD-camera the parameters of phase $(\delta, \theta)$ anisotropy were found. For objective assessment of histograms $N(q)$ of distributions $q \equiv\{\delta, \theta\}$ the set of statistical moments of the $1^{\text {st }}-4^{\text {th }}$ orders was determined ${ }^{24}$.

The series of figures 1-4 present the results of the technique of Jones-matrix reconstruction parameters $q \equiv\{\delta, \theta\}$ of polycrystalline bile films of $1^{\text {st }}$ group patients (fig. 1, fig. 3) and second one (fig.2, fig.4).
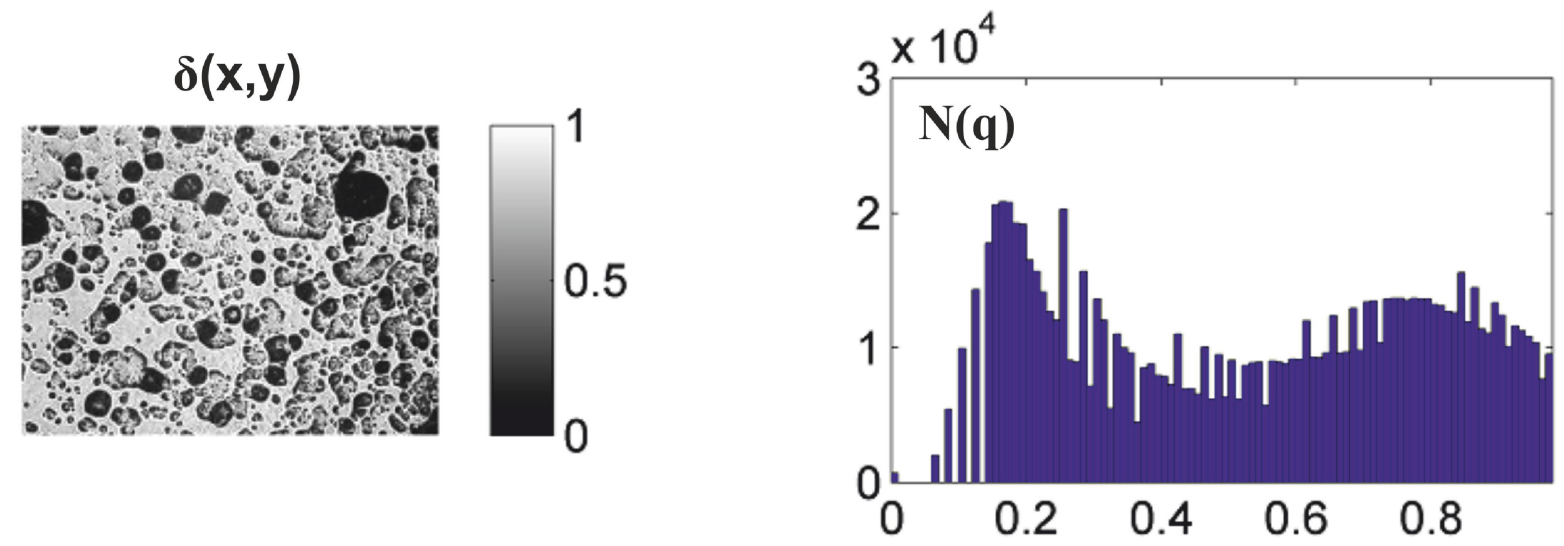

Figure 1. Coordinate distributions and the corresponding histogram of the values of phase shifts $\delta$, formed by polycrystalline film of bile of donors.
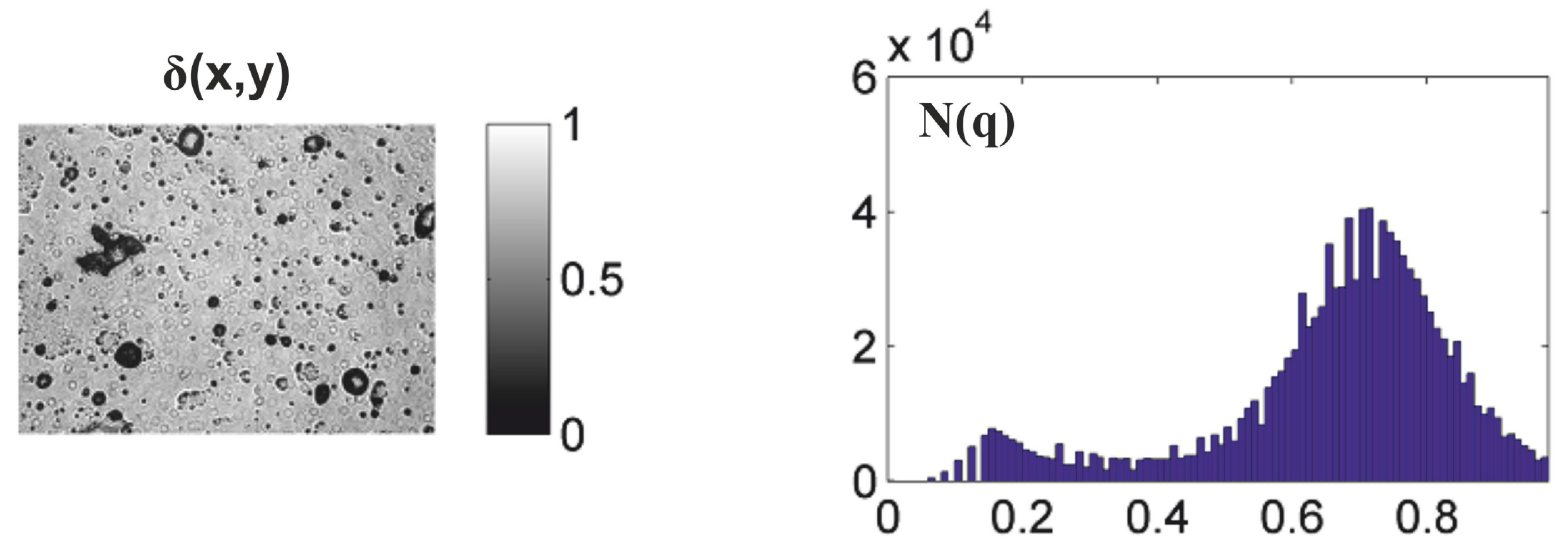

Figure 2. Coordinate distributions and the corresponding histogram of the values of phase shifts $\delta$, formed by polycrystalline film of bile of patients with cholelithiasis 

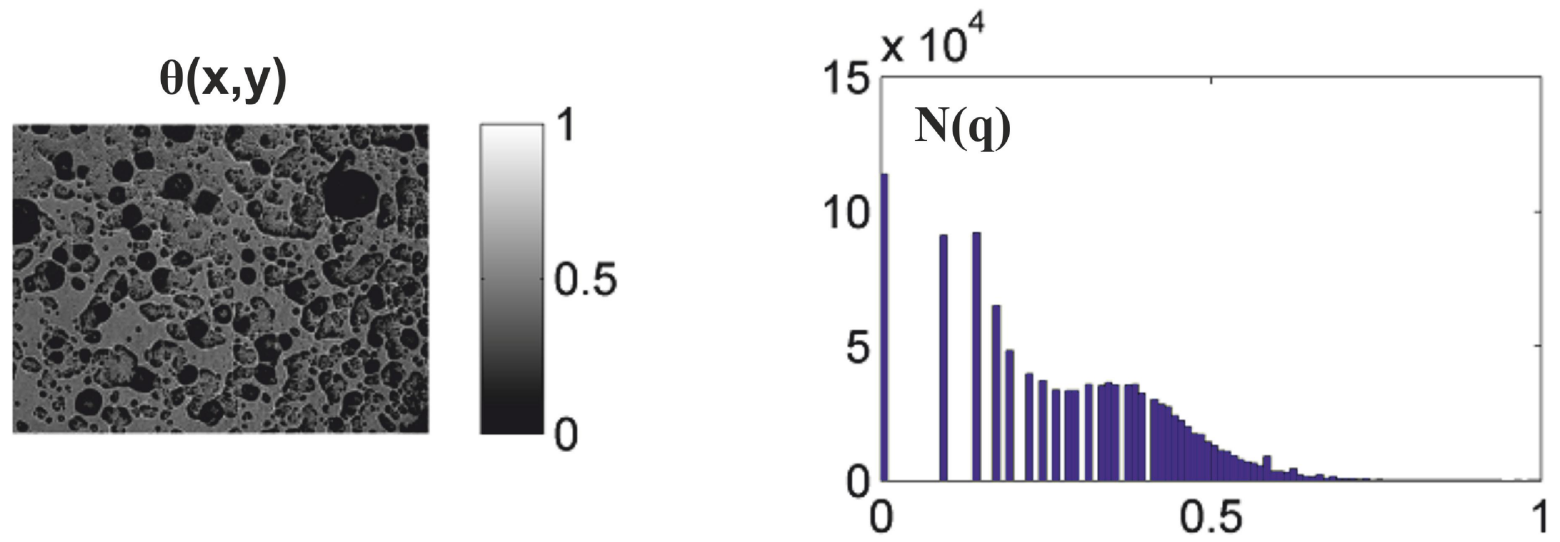

Figure 3. Coordinate distributions and the corresponding histogram of the values of phase shifts $\theta$, formed by polycrystalline film of bile of donors.
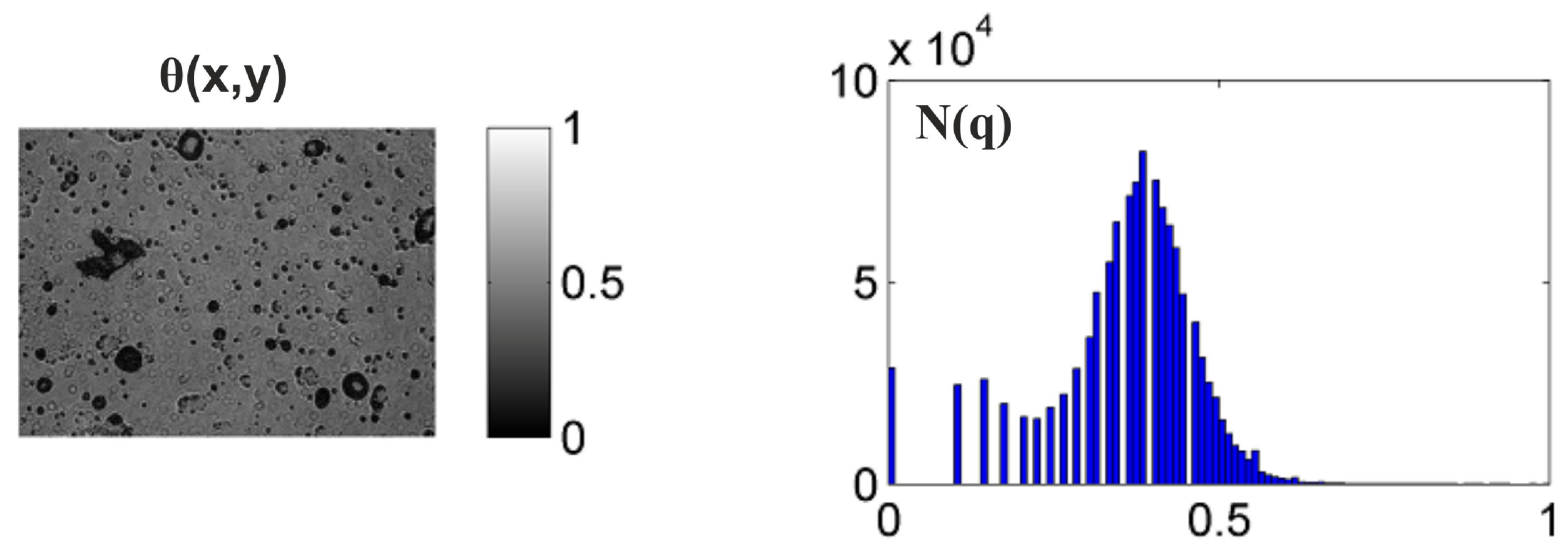

Figure 4. Coordinate distributions and the corresponding histogram of the values of phase shifts $\theta$, formed by polycrystalline film of bile of patients with cholelithiasis.

\subsection{Statistical intergroup analysis}

For the possible clinical application of both methods the following was determined for each group of samples ${ }^{29-31}$ :

- $\quad$ average (within group 1 and group 2) values of statistical moments $M_{i=1 ; 2 ; 3 ; 4}(q)$, their standard deviations $\pm \sigma$ and histograms $M\left(R_{i}\right)$ - Table 1 .

- traditional for probative medicine operational characteristics - sensitivity $\left(S e=\frac{a}{a+b} 100 \%\right)$, specificity $\left(S p=\frac{c}{c+d} 100 \%\right)$ and balanced accuracy $\left(A c=\frac{S e+S p}{2}\right)$, where $a$ and $b$ are the number of correct and wrong diagnoses within group 2; $c$ and $d$ - the same within group 1 - Table 2. 
Table 1. Average $\left(\bar{M}_{i=1 ; 2 ; 3 ; 4}\right)$ and standard deviations $( \pm \sigma)$ of statistical moments $M_{i=1 ; 2 ; 3 ; 4}$ of optical anisotropy distributions of bile films of groups 1 and 2

\begin{tabular}{|c|c|c|c|c|}
\hline \multirow{2}{*}{$q$} & \multicolumn{2}{|c|}{$\delta(n=47)$} & \multicolumn{2}{c|}{$\theta(n=47)$} \\
\cline { 2 - 5 } & group 1 & group 2 & group 1 & group 2 \\
\hline$M_{1}$ & $0.16 \pm 0.0079$ & $0.19 \pm 0.013$ & $0.079 \pm 0.0073$ & $0.11 \pm 0.0011$ \\
\hline$M_{2}$ & $0.19 \pm 0.013$ & $0.24 \pm 0.015$ & $0.14 \pm 0.009$ & $0.189 \pm 0.0145$ \\
\hline$M_{3}$ & $0.67 \pm 0.053$ & $0.43 \pm 0.041$ & $0.95 \pm 0.088$ & $0.54 \pm 0.036$ \\
\hline$M_{4}$ & $0.95 \pm 0.085$ & $0.46 \pm 0.042$ & $1.33 \pm 0.15$ & $0.77 \pm 0.062$ \\
\hline
\end{tabular}

Table 2 presents the parameters of information value of polarization-phase method of Jones-matrix reconstruction of phase anisotropy of polycrystalline films of bile.

Table 2. Operational characteristics of the method of Jones-matrix reconstruction of polycrystalline structure of bile films

\begin{tabular}{|c|c|c|c|}
\hline$q$ & $M_{i}$ & $\delta$ & $\theta$ \\
\hline \multirow{3}{*}{$A c\left(Z_{i}\right)$} & $M_{1}$ & $74 \%$ & $79 \%$ \\
\cline { 2 - 4 } & $M_{2}$ & $83 \%$ & $85 \%$ \\
\cline { 2 - 4 } & $M_{3}$ & $93 \%$ & $91 \%$ \\
\cline { 2 - 4 } & $M_{4}$ & $92 \%$ & $93 \%$ \\
\hline
\end{tabular}

The comparative analysis of operational characteristics of the method of Jones-matrix polarization reconstruction of polycrystalline structure of bile films revealed clinically optimal (highlighted in grey) parameters $\left\{\begin{array}{l}\delta \rightarrow M(\delta) \equiv\left\{A c\left(R_{3 ; 4}\right)=92 \%-93 \%\right\}, \\ \theta \rightarrow M(\theta) \equiv\left\{A c\left(R_{3 ; 4}\right)=90 \%-93 \%\right\} .\end{array}\right.$

The obtained results enable to state a rather high level of accuracy of Jones-matrix polarization-phase tomography. According to the criteria of probative medicine ${ }^{31}$ the parameters $M(\delta, \theta) \sim 90 \%-93 \%$ correspond to high quality.

\section{CONCLUSION}

The model of generalized optical anisotropy and the technique of Jones-matrix reconstruction of optical anisotropy parameters of polycrystalline bile films has been proposed. By means of statistic analysis the interconnection between the statistical moments of the $1^{\text {st }}-4^{\text {th }}$ order of anisotropy parameters of bile films and the changes in it structure of healthy people and cholelithiasis patients were determined. It has been proved the efficiency of Jones-matrix reconstruction of optical anisotropy parameters of bile films in diagnostics of early stages of cholelithiasis.

\section{REFERENCES}

[1]. V. V. Tuchin, L. Wang, and D. À. Zimnyakov [Optical Polarization in Biomedical Applications], SpringerVerlag (2006).

[2]. W. S. Bickel and W. M. Bailey, "Stokes vectors, Mueller matrices, and polarization of scattered light," Am. $J$. Phys. 53, 468-478 (1985).

[3]. S. Yau Lu and R. A. Chipman, "Interpretation of Mueller matrices based on polar decomposition," J. Opt. Soc. Am. A 13, 1106-1113 (1996).

[4]. N. Ghosh, M. Wood, and A. Vitkin, "Polarized light assessment of complex turbid media such as biological tissues using Mueller matrix decomposition,", Handbook of Photonics for Biomedical Science 9, 253-282 (2010). 
[5]. J. J. Gil, "Characteristic properties of Mueller matrices," J. Opt. Soc.Am. A 17, 328-334 (2000).

[6]. S.N.Savenkov, V.V. Marienko, E.A. Oberemok, O.I. Sydoruk, "Mueller matrix of optical anisotropic inhomogeneouse layer," Phys. Rev. E. 74, 605-607 (2006).

[7]. Angelsky, O. V., Bekshaev, A. Ya., Maksimyak, P. P., Maksimyak, A. P., Hanson, S. G., Zenkova, C. Yu., "Self-diffraction of continuous laser radiation in a disperse medium with absorbing particles," Optics Express 21(7), 8922-8938, (2013).

[8]. Angelsky, O.V., Besaha, R.N., Mokhun, A.I., Mokhun, I.I., Sopin, M.O., Soskin, M.S., "Singularities in vectoral fields," Proc. SPIE, 40-54, (1999).

[9]. R. A. Chipman, "Polarimetry" in Handbook of Optics: Vol. I- Geometrical and Physical Optics, Polarized Light, Components and Instruments, M. Bass, Ed., pp. 22.1-22.37, McGraw-Hill Professional, New York (2010).

[10]. M. K. Swami, H. S. Patel, and P. K. Gupta, "Conversion of $3 \times 3$ Mueller matrix to $4 \times 4$ Mueller matrix for nondepolarizing samples," Opt. Commun. 286(1), 18-22 (2013).

[11]. Angelsky, O. V., Bekshaev, A. Ya., Maksimyak, P. P., Maksimyak, A. P., Hanson, S. G., Zenkova, C. Yu., "Self-diffraction of continuous laser radiation in a disperse medium with absorbing particles," Optics Express 21(7), 8922-8938, (2013).

[12]. M. K. Swami, H. S. Patel, and P. K. Gupta, "Conversion of $3 \times 3$ Mueller matrix to $4 \times 4$ Mueller matrix for nondepolarizing samples," Opt. Commun. 286(1), 18-22 (2013).

[13]. N. Ghosh and I. A. Vitkin, "Tissue polarimetry: concepts, challenges, applications and outlook," J. Biomed. Opt. 16, 110801 (2011).

[14]. S. L. Jacques, "Polarized light imaging of biological tissues" in Handbook of Biomedical Optics, D. Boas, C. Pitris, and N. Ramanujam, Eds., pp. 649-669, CRC Press, Boca Raton, London, New York (2011).

[15]. N. Ghosh, M. F. G. Wood, and I. A. Vitkin, "Polarized light assessment of complex turbid media such as biological tissues via Mueller matrix decomposition," in Handbook of Photonics for Biomedical Science, V.V. Tuchin, Ed., pp. 253-282, CRC Press, Taylor \& Francis Group, London (2010).

[16]. O.V. Angelsky, S.G. Hanson, P.P. Maksimyak, A.P. Maksimyak, C.Yu. Zenkova, P.V. Polyanskii, and D.I. Ivanskyi, "Influence of evanescent wave on birefringent microplates," Opt. Express 25, 2299-2311 (2017).

[17]. Angelsky, O. V., Bekshaev, A. Ya., Maksimyak, P. P., Maksimyak, A. P., Hanson, S. G., Kontush, S. M., "Controllable generation and manipulation of micro-bubbles in water with absorptive colloid particles by $\mathrm{CW}$ laser radiation," Opt. Express 25, 5232-5243 (2017).

[18]. V. A. Ushenko, M. P. Gorsky, "Complex degree of mutual anisotropy of linear birefringence and optical activity of biological tissues in diagnostics of prostate cancer," Optics and Spectroscopy, 115(2), 290-297 (2013).

[19]. V. A. Ushenko, M. S. Gavrylyak, "Azimuthally invariant Mueller-matrix mapping of biological tissue in differential diagnosis of mechanisms protein molecules networks anisotropy," Proc. SPIE 8812, Biosensing and Nanomedicine VI, 88120Y (2013).

[20]. V. A. Ushenko, N. I. Zabolotna, S. V. Pavlov, D. M. Burcovets, O. Yu. Novakovska, "Mueller-matrices polarization selection of two-dimensional linear and circular birefringence images," Proc.SPIE 9066, (2013).

[21]. V. A. Ushenko, A. V. Dubolazov, "Correlation and self similarity structure of polycrystalline network biological layers Mueller matrices images," Proc. SPIE 8856, (2013).

[22]. Yu. A. Ushenko, V. A. Ushenko, A. V. Dubolazov, V. O. Balanetskaya, N. I. Zabolotna, "Mueller-matrix diagnostics of optical properties of polycrystalline networks of human blood plasma," Optics and Spectroscopy 112(6), 884-892 (2012).

[23]. Angelsky, P. O., Ushenko, A. G., Dubolazov, A. V., Sidor, M. I., Bodnar, G. B., Koval, G., Trifonyuk, L., "The singular approach for processing polarization-inhomogeneous laser images of blood plasma layers," Journal of Optics, 15(4), 044030 (2013).

[24]. Dubolazov, A. V., Marchuk, V., Olar, O. I., Bachinskiy, V. T., Vanchuliak, O. Y., Pashkovska, N. V., Kostiuk, S. V., "Multiparameter correlation microscopy of biological fluids polycrystalline networks," In Eleventh International Conference on Correlation Optics, International Society for Optics and Photonics, pp. 90661Y90661Y (2013).

[25]. Ushenko, O., Dubolazov, A., Balanets' ka, V., Karachevtsev, A., Sydor, M., "Wavelet analysis for polarization inhomogeneous laser images of blood plasma," Proc. SPIE. Vol. 8338 (2011).

[26]. Ushenko, V. A., O. V. Dubolazov, A. O. Karachevtsev, "Two wavelength Mueller matrix reconstruction of blood plasma films polycrystalline structure in diagnostics of breast cancer," Applied optics 53(10), B128-B139 (2014). 
[27]. V. A. Ushenko, O. V. Dubolazov, A. O. Karachevtsev, "Two wavelength Mueller matrix reconstruction of blood plasma films polycrystalline structure in diagnostics of breast cancer," Applied Optics. 53(10), B128B139 (2014).

[28]. A. Gerrard and a J. Burch, "Introduction to matrix methods in optics," Courier Corporation, (2012).

[29]. L. Cassidy, "Basic concepts of statistical analysis for surgical research," Journal of Surgical Research 128, 199206 (2005).

[30]. C. S. Davis, [Statistical methods of the analysis of repeated measurements], New York: Springer-Verlag, 744, (2002).

[31]. A. Petrie, B. Sabin, [Medical Statistics at a Glance,] Blackwell Publishing, 157, (2005). 